\title{
Tumor maligno da bainha de nervo periférico envolvendo raízes nervosas do terceiro segmento medular lombar em um cão
}

\section{Canine malignant peripheral nerve sheath tumor involving nerve roots of the third lumbar spinal cord segment}

\author{
Elisângela Olegário da Silva ${ }^{1 *}$; Fabiana Pessuto Zanoni²; Raquel Beneton Ferioli; \\ Mirian Siliane Batista de Souza ${ }^{4}$; Giovana Wingeter Di Santis ${ }^{5}$
}

\section{Resumo}

Tumores malignos da bainha de nervo periférico (TMBNP) em raízes nervosas espinhais são incomuns em cães. Relata-se o caso de um cão, sem raça definida, nove anos de idade, não castrado, com histórico de incoordenação em membros pélvicos e retenção urinária há aproximadamente uma semana. Ao exame clínico constatou-se déficit proprioceptivo e hiperreflexia patelar bilaterais. Durante a celiotomia exploratória constatou-se uma massa intensamente vascularizada e aderida aos segmentos vertebrais lombares. Estabeleceu-se plano terapêutico e o animal foi tratado com fluidoterapia, anti-inflamatório e analgésico. No entanto, diante do agravamento dos sinais clínicos, o proprietário optou pela realização da eutanásia do animal. Ao exame necroscópico observou-se massa em cavidade abdominal, aderida ao corpo dos segmentos vertebrais L3 e L4, porém sem invasão do canal medular. Ao exame microscópico da massa observou-se proliferação de células ovaladas a alongadas, com citoplasma eosinofílico pálido e pouco delimitado. Havia moderada anisocariose e elevado índice mitótico. A matriz extracelular estava disposta em feixes entrelaçados e com arranjo espiralado, entremeado por delicado a moderado estroma. O exame imuno-histoquímico evidenciou marcação positiva para os anticorpos anti-GFAP, anti-S100 e anti-vimentina, e marcação negativa para anti-fator VIII, anti- $\alpha$-actina de músculo liso e anticitoqueratina. Diante dos achados histopatológicos e imuno-histoquímicos concluiu-se o diagnóstico como tumor maligno de bainha de nervo periférico.

Palavras-chave: TMBNP, raiz nervosa espinhal, cão

\begin{abstract}
Malignant peripheral nerve sheath tumors (MPNST) involving spinal nerve roots are uncommon in dogs. A nine-year old, intact, mixed-breed dog, demonstrated clinical signs of incoordination in the pelvic limbs and micturition for approximately one week. Clinical examination revealed proprioceptive deficits and bilateral patellar hyperreflexia. During exploratory celiotomy a mass was observed adhered to the lumbar vertebral segments. Medical therapy was initiated, but neurological signs were progressive, and the owner opted for euthanasia. Gross examination showed that the mass in the abdominal cavity was attached to the lumbar segments L3 and L4, causing bone lysis in L3, but showed no tumor invasion into the spinal canal. Microscopic features were characterized by prominent proliferation of ovoid and fusiform cells with poorly defined cytoplasm arranged in interlacing bundles and concentric whorls. The

1 Residente Patologia Animal. Universidade Estadual de Londrina, UEL, Londrina, PR. E-mail: elivet02@gmail.com

2 Residente Clínica Cirúrgica de Animais de Companhia, UEL, Londrina, PR.

${ }^{3}$ Mestranda em Patologia Animal, Faculdade de Medicina Veterinária e Zootecnia, Universidade Estadual Paulista, FMVZ/UNESP, Botucatu, São Paulo, SP. E-mail: raquel_benetonferioli@yahoo.com.br

${ }^{4}$ Prof $^{\mathrm{a}}$. Dr ${ }^{\mathrm{a}}$. do Dept ${ }^{\mathrm{o}}$ de Clínicas Veterinárias, DCV, UEL, Londrina, PR. E-mail: msiliane@uel.br;

${ }^{5}$ Prof $^{\mathrm{a}}$. Dr ${ }^{\mathrm{a}}$. do Dept ${ }^{\mathrm{o}}$ de Medicina Veterinária Preventiva, DMVP, UEL, Londrina, PR. E-mail: giovanaws@uel.br
\end{abstract}

* Autor para correspondência 
cells were embedded in a delicate to moderate collagenous stroma and moderate anisokariose and high mitotic activity were noted. The immunohistochemical assay showed positive staining for GFAP, S-100 protein and vimentin, and negative staining for factor VIII, $\alpha$-actin and citokeratine. The definitive diagnosis of malignant peripheral nerve sheath tumor was made on the basis of the histological and immunohistochemical findings.

Key words: MPNST, spinal nerve root, dog

\section{Introdução}

Tumores da bainha dos nervos periféricos (TBNP) são infrequentes nos animais domésticos e são mais relatados em caninos e bovinos (SUMMERS; CUMMINGS; DeLAHUNTA, 1995). Originam-se das células de Schwann, fibroblastos perineurais ou ambos. Na medicina veterinária, não há diferenciação de padrões e subclassificações dos TBNP, sendo referidos como schwannoma ou tumor de bainha de nervo (HENDRICK et. al., 1998; CHIJIWA; UCHIDA; TATEYANNA, 2004).

Em cães, os TBNP são mais comuns nos nervos do plexo braquial, mas podem afetar o plexo lombossacral, os nervos cranianos, principalmente vestibulococlear, trigêmio e oculomotor, e menos comumente nervos e raízes nervosas espinhais (CHIJIWA; UCHIDA; TATEYANNA,2004; LeCOUTEUR; WITHROW, 2007). Macroscopicamente, apresentam-se como massas solitárias, ou como espessamento varicoso ao longo dos troncos nervosos, variando de firme a macio (gelatinoso), de coloração branca a acinzentada (KOESTNER; HIGGINS, 2002). Em animais com TBNP, nos quais se realiza excisão sem margem cirúrgica, os tumores tendem a recidivar com características de malignidade (LeCOUTEUR; WITHROW, 2007).

Os tumores malignos de bainha de nervos periféricos (TMBNP) são incomuns em cães e raros em gatos (LeCOUTEUR; WITHROW, 2007). Suas características macroscópicas são similares aos TBNP, no entanto apresentam invasividade, aderência às estruturas subjacentes e metástases. A média de idade dos cães afetados é nove anos e é descrita a predisposição de animais da raça Golden Retriever ao desenvolvimento de TMBNP (GOLDSCHMIDT; HENDRICK, 2002).
Exames complementares de imagem como a radiografia simples e a mielografia são essenciais quando há suspeita de neoplasia em nervos espinhais ou raízes nervosas, evidenciando possíveis invasões do canal medular (LeCOUTEUR; WITHROW, 2007).

O diagnóstico definitivo é obtido por meio do exame histopatológico e imunohistoquímico. Microscopicamente, os TMBNP apresentam vários padrões morfológicos, anaplasia, elevado índice mitótico, necrose, invasão de tecidos adjacentes e metástase em órgãos distantes como o pulmão (STOICA; TASCA; KIM, 2001). Os principais diagnósticos diferenciais de TMBNP são o hemangiopericitoma, fibrossarcoma, histiocitoma fibroso maligno, leiomiossarcoma, rabdomiossarcoma e sarcoma sinovial. Em muitos casos, os padrões histológicos são semelhantes, tornando a realização de um painel imunohistoquímico imprescindível para o diagnóstico definitivo. Os TMBP apresentam marcação positiva para o anticorpo anti-vimentina e dependendo do padrão morfológico, marcação variável para os anticorpos anti-GFAP (Glial Fibrillary Acid Protein) e anti-S100 (GOLDSCHMIDT; HENDRICK, 2002; GROSS et.al., 2005).

$\mathrm{O}$ tratamento dos TMBNP é limitado à excisão cirúrgica, porém, na maioria dos animais o tumor apresenta-se inoperável devido à invasividade do neoplasma em tecidos adjacentes. A quimioterapia pode ser utilizada como tratamento paliativo. A combinação dos quimioterápicos vincristina, doxorrubicina e ciclofosfamida tem sido recomendada (LeCOUTEUR; WITHROW, 2007).

O objetivo deste trabalho é relatar um caso de TMBNP envolvendo raízes nervosas da terceira vértebra lombar e seus aspectos clínicos, histopatológicos e imunohistoquímicos. 


\section{Relato de Caso}

Um canino, fêmea, sem raça definida, nove anos de idade, não castrada foi atendida no Hospital Veterinário da Universidade Estadual de Londrina com histórico de dificuldade de locomoção e retenção urinária há uma semana. Ao exame clínico, constatou-se que o animal apresentava ataxia de membros posteriores, déficit propioceptivo e hiperreflexia patelar bilaterais. Foi encaminhado para a realização de exame ultrassonográfico no qual se observou massa heterogênea localizada caudalmente ao rim esquerdo. Durante a celiotomia exploratória constatou-se uma massa intensamente vascularizada e aderida aos segmentos vertebrais lombares, impossibilitando sua excisão. Estabeleceuse plano terapêutico e o animal foi tratado com fluidoterapia, anti-inflamatório e analgésico. Diante do agravamento dos sinais clínicos, houve indicação da eutanásia e o proprietário concordou com sua realização.

Ao exame necroscópico observou-se massa em cavidade abdominal, esbranquiçada, firme e aderida ao corpo dos segmentos vertebrais $\mathrm{L} 3 \mathrm{e} \mathrm{L} 4$, medindo $7 \times 6,5 \times 6 \mathrm{~cm}$. Realizou-se exame radiográfico post mortem, visualizando-se lise óssea no corpo vertebral L3 (Figura 1A). Ao corte, confirmou-se que o tumor infiltrava e causava lise óssea no corpo vertebral L3, porém sem invasão do canal medular, onde se observou coágulo sanguíneo volumoso comprimindo o segmento medular (Figura 1B). Fragmentos foram coletados e fixados em solução de formol a $10 \%$ tamponado. $\mathrm{O}$ osso foi submetido ao processo de descalcificação. Após fixação, o material foi encaminhado para processamento histológico de rotina. Para avaliação imunohistoquimica foi feito um painel com os anticorpos primários anti-fator VIII, GFAP, vimentina, $\alpha$-actina de músculo liso, citoqueratina, proteína S-100, utlizando protocolos, controles positivos e negativos conforme as orientações dos fabricantes.
Ao exame microscópico da massa observou-se proliferação de células ovaladas a alongadas, com citoplasma eosinofílico pálido e pouco delimitado, núcleos vesiculosos e nucléolos conspícuos, presença de células hipercromáticas e média de 6,3 mitoses por campo de maior aumento (400x). As células se dispunham ora em feixes ondulados entrelaçados, ora em arranjos espiralados a neuroides, entremeados por estroma colagenoso delicado e por extensas áreas de necrose (Figura 1C e 1D). Na avaliação da vértebra espinhal, observouse lise óssea e proliferação de células neoplásicas com características similares às da massa (Figura 1E). No exame imuno-histoquímico, obteve-se marcação citoplasmática fortemente difusa para vimentina (Figura 1F), moderadamente positiva e difusa para GFAP (Figura 1G) e S-100 (Figura $1 \mathrm{H})$, e marcação negativa para fator VIII, $\alpha$-actina de músculo liso e citoqueratina, considerando as células neoplásicas como observado na tabela 1 .

TMBNP em nervos e raízes espinhais são incomuns em cães (CHIJIWA; UCHIDA; TATEYANNA, 2004) e são uma das principais causas de claudicação neurogênica crônica em cães, porém em estágios iniciais são indistinguíveis de outras doenças. O tratamento dos TMBNP é limitado à excisão cirúrgica ampla, pois tanto em humanos como animais, não apresentam boa resposta frente à radioterapia e à quimioterapia (LeCOUTEUR; WITHROW, 2007). No presente caso, os sinais clínicos apresentados pelo animal foram possivelmente ocasionados por compressão dos segmentos medulares L2 e L3 pelo coágulo presente no canal medular. A infiltração de tecido ósteomuscular e a localização tumoral impossibilitavam a excisão cirúrgica, de forma a justificar a indicação de eutanásia do animal. Na dissecção da massa tumoral não foi possível identificar a raiz nervosa da qual se desenvolveu o tumor, no entanto, pela localização da massa tumoral, acredita-se que o tumor originou-se de uma das raízes nervosas do segmento medular L3. 
Figura 1. Tumor maligno de bainha de nervo periférico envolvendo raízes nervosas do terceiro segmento medular lombar. A-radiografia post mortem evidenciando lise óssea em L3. B- massa esbranquiçada, consistência firme, invasiva, causando lise óssea em L3, porém sem invasão do canal medular. Presença de coágulo comprimindo os segmentos medulares L2 e L3.C-disposição das células neoplásicas em feixes entrelaçados e arranjos espiralados a neuróides, H\&E, objetiva de 10x. D-células neoplásicas ovaladas a alongadas, entremeadas por delicado estroma colagenoso. Moderada anisocariose, H\&E, objetiva de 40x. E-invasão de células neoplásicas no tecido ósseo, H\&E, objetiva de 10x. F- marcação forte e difusa para o anticorpo anti-vimentina, método do polímero, contracoloração com Hematoxilina de Harris, objetiva de 40x. G-marcação moderada e difusa para o anticorpo anti-GFAP, método do polímero, contracoloração com Hematoxilina de Harris, objetiva de 40x. H- marcação moderada e difusa para o anticorpo anti-S100, método do polímero, contracoloração com Hematoxilina de Harris, objetiva de 40x.

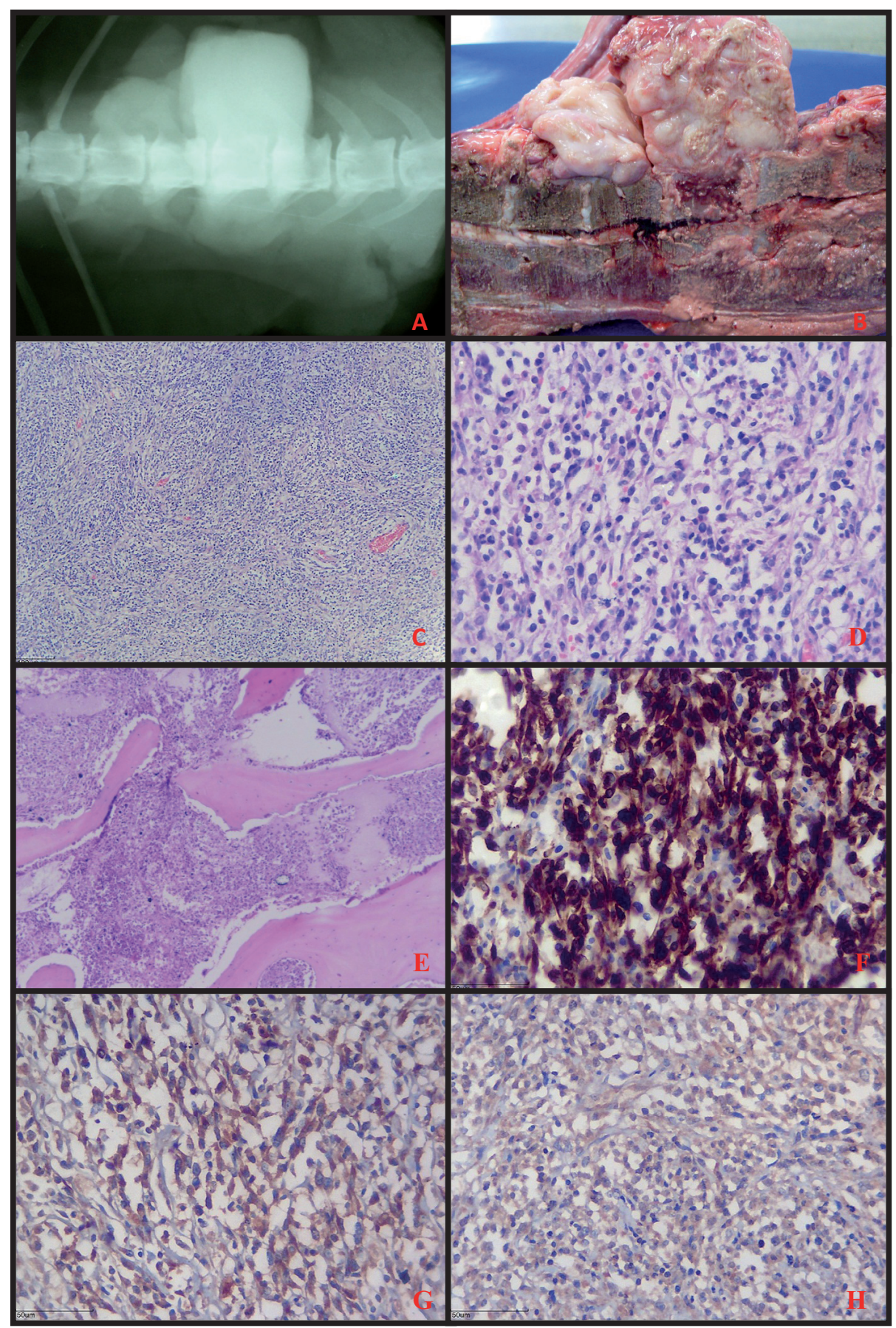

Fonte: Elaboração dos autores. 
Tabela 1. Resultados da marcação imuno-histoquímica do tumor maligno da bainha de nervo periférico envolvendo raízes nervosas do terceiro segmento medular lombar em um cão.

\begin{tabular}{llll}
\hline Anticorpos & Fabricante & Diluição & Resultado \\
\hline GFAP (policlonal) & Zymed ${ }^{\circledR}$ & $1: 100$ & ++ \\
Vimentina (V9) & Invitrogen® & $1: 100$ & +++ \\
S100 (policlonal) & Zymed ${ }^{\circledR}$ & $1: 100$ & ++ \\
Fator VIII (policlonal) & Dako & $1: 2000$ & - \\
Citoqueratina (AE1/AE3) & Invitrogen ${ }^{\circledR}$ & $1: 50$ & - \\
$\alpha$-actina de músculo liso & Santa Cruz & $1: 1200$ & - \\
$(1 \mathrm{~A} 4)$ & & & \\
\hline
\end{tabular}

++ (moderadamente positivo), +++ (fortemente positivo), - (negativo).

Fonte: Elaboração dos autores.

Nos TBNP caninos, a presença do clássico padrão histológico Antoni A e Antoni B não é predominante como nos tumores humanos(STOICA; TASCA; KIM, 2001). Os TMBNP apresentam acentuado pleomorfismo, alta celularidade, necrose, hemorragia, elevado índice mitótico, comportamento invasivo e podem desenvolver metástase em órgãos distantes. Assim como em humanos, diferenciações divergentes para padrões epitelióide, melanótico, cartilaginoso, osteogênico e epitelial glandular tem sido observadas em TBNPM de cães e indicam um pior prognóstico (CHIJIWA, UCHIDA; TATEYANNA, 2004; PATNAIK et. al., 2002). Acredita-se que a diferenciação mesenquimal observada em TMBNP ocorra devido à migração de células da crista neural que se diferenciam em células mesenquimais multipotenciais, podendo dar origem a diferentes tecidos como ossos e cartilagem, e que os componentes epiteliais surgem das células de Schwann ou células mesoectodérmicas, as quais se originam intrínsecas aos nervos periféricos (PATNAIK et. al., 2002). No presente caso, o tumor não apresentava diferenciações divergentes, nem pleomorfismo celular acentuado, no entanto observaram-se extensas áreas de necrose, elevado índice mitótico e comportamento invasivo causando lise e infiltração óssea.

A marcação imuno-histoquímica dos TMBNP é variável devido à diversidade de padrões morfológicos das células e de diferenciações presentes. Apenas a imuno-expressão de vimentina é constantemente observada, enquanto marcação para GFAP e S-100 pode ser ausente ou variar de fraca e multifocal a forte e difusa (CHIJIWA; UCHIDA; TATEYANNA, 2004; GROSS et. al., 2005; OTTINGER; LINDBERG; EKMAN, 2009). A ausência de imunomarcação para GFAPe S-100 pode dificultar o diagnóstico diferencial de fibrossarcoma, mixossarcoma e hemangiopericitoma. Nestes casos, indica-se utilizar um anticorpo que marque lâmina basal, pois estes sarcomas, em contraste com os TBNP, não apresentam lâmina basal (GROSS et al., 2005). A marcação forte e difusa para vimentina, GFAP e S-100 no presente relato, assim como a negatividade para citoqueratina, $\alpha$-actina e fator VIII foram decisivas para diagnóstico definitivo de TBNP, enquanto o alto índice mitótico, a invasão de tecidos adjacentes e a presença de extensas áreas de necrose foram a base para a caracterização da malignidade do neoplasma, reforçando a importância de uma minuciosa avaliação histopatológica.

O prognóstico para cães com TMBNP envolvendo raízes nervosas espinhais é ruim devido à localização, ao comportamento agressivo e a falta de resposta terapêutica. O diagnóstico definitivo é obtido por meio do exame histopatológico e o exame imuno-histoquímico torna-se essencial para confirmação devido à diversidade morfológica dos TMBNP caninos. 


\section{Referências}

CHIJIWA, K.; UCHIDA, K.; TATEYAMA, S. Immunohistochemical evaluation of canine peripheral nerve sheath tumors and other soft tissue sarcomas. Veterinary Pathology, USA, v. 41, n. 4, p. 307-318, 2004.

GOLDSCHMIDT, M. H.; HENDRICK, M. J. Tumors of the skin and soft tissues. In: MEUTEN, J. (Ed.). Tumors in domestic animals. 4. ed. Iowa: Blackwell Publishing Company, 2002. p. 95-96.

GROSS, T. L.; IHRKE, P. J.; WALDER, E. J.; AFFOLTER, V. K. Skin diseases of the dog and cat: clinical and histopathologic diagnosis. 2. ed. Iowa: Blackwell Publishing Company, 2005, p. 789-796.

HENDRICK, M. J.; MAHAFFEY, E. A.; MOORE, F. M.; VOS, J. H.; WALDER, E. J. World health organization international histological classification of mesenchymal tumors of skin and soft tissues of domestic animals. Second series. Washington DC: Armed Forces Institute of Pathology American Registry of Pathology, 1998. v. 2, p. 26-27.

KOESTNER, A.; HIGGINS, R. J. Primary tumors of the peripheral nervous system. In: MEUTEN, J. (Ed.). Tumors in domestic animals. 4. ed. Iowa: Blackwell Publishing Company, 2002. p. 731-735.
LeCOUTEUR, R. A.; WITHROW, S. J. Tumors of the nervous system. In: WITHROW, S. J.; VAIL, D. M. Withrow \& macewen's small animal clinical oncology. 4. ed. St Louis: Saunders Elsevier, 2007. p. 676-680.

OTTINGER, T.; LINDBERG, R.; EKMAN, S. Malignant acoustic schwannoma in a dog. Journal of Veterinary Diagnostic Investigation, Davis, v. 21, n. 1, p. 129-132, 2009.

PATNAIK, A. K.; ZACHOS, T. A.; SAMS, A. E.; AITKEN, M. L. Malignant nerve-sheath tumor with divergent and glandular differentiation in a dog: case report. Veterinary Pathology, USA, v. 39, n. 3, p. 406409, 2002.

STOICA, G.; TASCA, S. I.; KIM, H-T. Point of neu oncogene in animal peripheral nerve sheath tumors. Veterinary Pathology, USA, v. 38, n. 6, p. 679-688, 2001.

SUMMERS, B. A.; CUMMINGS, J. F.; DeLAHUNTA, A. Veterinary neuropathology. St. Louis: Mosby, 1995. p. $472-501$. 